Functional Neural =Transplantation IV - chapter 20.

\title{
Recruitment of endogenous CNS stem cells for regeneration in demyelinating disease
}

Natalia A Murphy and Robin JM Franklin

Wellcome Trust-Medical Research Council Cambridge Stem Cell Institute, and Department of Clinical Neurosciences, Clifford Allbutt Building, Cambridge Biomedical Campus, University of Cambridge, Cambridge CB2 OAH, UK 


\begin{abstract}
Demyelinating diseases, such as Multiple Sclerosis (MS), are responsible for a significant portion of the neurological disability burden worldwide, especially in young adults.

Demyelination can be followed by a spontaneous regenerative process called remyelination, in which new myelin sheaths are restored to denuded axons. However, in chronic demyelinating disease such as MS, this process becomes progressively less efficient. This chapter reviews the biology of remyelination and the rationale and strategies by which it can be enhanced therapeutically in acquired demyelinating disease.
\end{abstract}

Keywords: remyelination, adult stem cells, OPC, demyelination, myelin, oligodendrocyte, Multiple Sclerosis, 


\section{Introduction}

Despite the existence of adult CNS stem and progenitor cells, the fully developed mammalian central nervous system is commonly viewed to have little to no regenerative capacity. However, the response to demyelination provides an excellent example of complete regeneration within the adult CNS. This chapter aims to discuss the CNS endogenous regeneration potential and ways of enhancing it, focusing specifically on demyelinating disease.

First, we review the biology of myelination, and remyelination in response to a demyelinating insult. Next, we present the most important examples of demyelinating disease and discuss why and how in these cases remyelination fails. Finally, we discuss the rationale and strategies of augmenting the endogenous regenerative potential of the CNS, and review recent advances in this field. We describe how targeting endogenous stem cells for regeneration is a viable and attractive alternative to cell transplant therapies in demyelinating disease.

\section{Overview: Myelination and remyelination}

\subsection{The myelinated CNS - an evolutionary milestone}

Myelination, the ensheathment of axons in a compacted, lipid rich, multi-layered insulating membrane, was an evolutionary milestone for craniate vertebrates - it allowed them to develop complex predatory and escape behaviors, while increasing their body size (Zalc et al, 2008). Myelin serves a multitude of functions in the CNS. Crucially, the myelin sheath creates a region of high resistance and low capacitance around the myelinated part of the axon, enabling saltatory conduction (Felts et al, 1997) and increasing axonal transmission speed 20-100 times (Nave \& Werner 2014), while optimizing neurotransmitter efficiency. As well as accelerating conduction, myelination offers trophic (Griffiths et al 1998, Lappke-Siefke et al, 2003) and metabolic (Lee et al 2012, Funfshilling et al, 2014) support to the axon, making it an essential neuroprotective element of the CNS. Finally, changes in myelination throughout adult life have recently been proposed as a mechanism of functional plasticity within the adult CNS, implicated in memory and learning (reviewed in Bergles and Richardson, 2016 and Tomassy et al, 2016). 
These functions, together with the fact that white matter makes up over $40 \%$ of the human brain (Snaidero and Simons, 2014), point toward an integral role of myelin in the adult mammalian brain, as evidenced by the devastating effects of demyelinating diseases (see below).

\subsection{Developmental myelination}

Myelin in the CNS is produced by oligodendrocytes. These cells arise from Oligodendrocyte Progenitor Cells (OPCs) which proliferate, migrate and differentiate, extending cytoplasmic sheaths towards axons which they are to myelinate (reviewed in Emery and Lu, 2015). Once axonal contact is established, oligodendrocyte sheaths enwrap the axon, and compact around it forming mature myelin (reviewed in Simons and Nave 2016). Each oligodendrocyte can extend up to 80 myelinating processes (Chong et al, 2012), and almost never myelinates neighboring paranodes within the same axon (Young et al, 2013).

In rodents, myelination peaks around postnatal day 14 and is largely completed by day 60 (Rivers et al, 2008). In contrast, in humans developmental myelination is prolonged and peaks around the $3^{\text {rd }}-5^{\text {th }}$ year of life (Yeung et al, 2014), continuing into the second decade (Giedd et al, 1999).

\subsection{The Oligodendrocyte Progenitor Cell}

Oligodendrocyte progenitor cells (OPC) arise in multiple independent populations from distinct domains of the neuroepithelium during development (reviewed in Fancy et al, 2011a) and migrate extensively to populate the CNS and differentiate into oligodendrocytes. $A$ proportion of OPCs remain in the adult CNS in the undifferentiated state. These cells, characterized by the expression of NG2, A2B5 and Pdgfra (Horner et al, 2000; Pringle et al, 1992; Raff et al, 1986) are widespread in the grey and white matter, and amount to 5-8\% of all the cells in the mature CNS (Levine et al, 2001). They are the main proliferating cell population in the CNS, and an essential reservoir of progenitors for remyelination (see below). As such, they have been viewed as adult stem cells of the CNS (Crawford et al, 2014). Indeed, they continue to proliferate throughout life, demonstrating robust capacity for self-renewal. Lineage 
tracing studies have confirmed their multipotency, showing that OPCs can differentiate into oligodendrocytes and astrocytes in development, and into oligodendrocytes, astrocytes, and Schwann cells (the neural crest derived myelinating cells of the PNS) in adult life (Kang et al, 2010; Rivers et al, 2008; Zawadzka et al, 2010; Zhu et al, 2008). These features provide a strong basis to consider the OPC as a type of adult stem cell, a helpful framework within which to study their behaviour in the context of cancer, ageing and regeneration. OPCs can also be generated in adult life from neural stem cells of the subventricular zone (SVZ), and have been shown to contribute to remyelination in the vicinity of the SVZ (Jabłońska et al, 2010; NaitOumesmar et al, 1999). However, as the structure of the human SVZ is very different to the rodent one (Fietz et al, 2012; Lim and Alvarez-Buylla, 2016), the relevance of this finding to human remyelination is unclear.

Finally, as well as a central role in myelination and remyelination, OPCs have been shown to play physiological roles in the resting adult CNS, notably in modulating synaptic transmission (discussed in Dimou and Gallo, 2015).

\subsection{Remyelination - the default response to a demyelinating insult}

In response to demyelination, the adult CNS regenerates myelin sheaths restoring saltatory conduction (Smith et al, 1979) and reversing functional deficits (Duncan et al, 2009; Jeffery and Blakemore, 1997; Liebetanz and Merkler, 2006) in a process called remyelination. This is a unique example of regeneration in an otherwise poorly regenerating central nervous system, and is the default outcome in both experimental models of demyelination and in naturallyoccurring CNS diseases, including those of humans (Lasiene et al, 2008; Patrikios et al, 2006; Smith and Jeffery, 2006). Remyelination is achieved by OPCs, and broadly follows the principles of developmental myelination, with some exceptions (Fancy et al, 2011a).

In response to myelin and oligodendrocyte damage, resident astrocytes and microglia produce factors which initiate the inflammatory response and activate OPCs within and around the damaged area. Activated OPCs undergo a change in morphology (Levine and Reynolds 1999), upregulate specific activation genes, re-express developmental markers (Fancy et al, 
2004; Moyon et al, 2016; Watanabe et al, 2004) and become more responsive to mitogens produced by surrounding cells (Hinks and Franklin, 1999).

Using environmental cues, activated OPCs proliferate and migrate into and within the lesion. This constitutes the recruitment phase of remyelination. In the next phase of remyelination, OPCs exit the cell cycle and differentiate into oligodendrocytes. These cells establish contact with denuded axons, and extend cytoplasmic processes, which wrap around them and form a compact myelin sheath. Apart from the smallest diameter myelinated axons, remyelinated axons are characterized by a thinner myelin sheath relative to their diameter (i.e. higher g ratio). The functional significance of this finding is currently unknown. The g ratio appears to be unchanged if the remyelination is carried out by SVZ derived OPCs, although this may be due to the small diameter of the axons of the corpus callosum (Stidworthy et al, 2003).

\section{Demyelination}

\subsection{Myelin disorders}

Many myelin disorders have been described in human and non-human species (reviewed in Duncan and Radcliff, 2016). These can be broadly divided into primary genetic disorders of myelination, acquired inflammatory (including autoimmune) disorders, toxic disorders, and traumatic loss of myelin. The myelin loss that follows primary axon degeneration is sometimes called secondary demyelination, but this is a misleading term for what should be referred to as Wallerian degeneration.

Genetic disorders of myelination can be due to inherent errors in lipid metabolism (e.g. X linked adrenoleukodystrophy), mutations of essential myelin genes (e.g., Pelizaeus Merzbacher disease), lysosomal storage disorders (e.g. Krabbe's disease) or mitochondrial mutations (e.g. Kearns-Sayre syndrome). As well as frank demyelination, these disorders often involve abnormalities in developmental myelination and lead to hypomyelination or dysmyelination. As the causes of these diseases are inherent to the oligodendroglial lineage, they are not amenable to endogenous remyelination enhancement and will not be discussed further. 


\subsection{Consequences of demyelination}

True demyelinating disease is characterized by denuded but otherwise intact axons. This can happen either because the myelin sheaths themselves have been damaged, or due to death of oligodendrocytes that produce and maintain them. A common pathological alteration of the myelin sheath is vacuolation - fluid seen in extracellular space between layers of myelin. Vacuolation may in turn lead to myelin sheaths becoming dissociated from the axon, resulting in axon denudation. Denuded axons temporarily stall action potential transmission (Felts et al, 1997) and the axonal membrane must be modified to allow for slower and more energy demanding, continuous action potential conduction. In addition, naked axons are more vulnerable, as they no longer have the trophic and metabolic support and barrier of the surrounding myelin sheath. If the axon is not quickly remyelinated it remains vulnerable to degeneration, which in turn leads to irreversible functional deficits (Franklin et al, 2012).

\subsection{Acquired demyelinating disorders}

The most common demyelinating disease in humans, affecting 2-2.5 million people worldwide (Milo and Kahana, 2010), is Multiple Sclerosis (MS). MS is an autoimmune disease of the brain, optic nerve and spinal cord, where focal lymphocytic infiltration leads to damage of myelin and axons (Compston and Coles, 2008). After an initial relapsing-remitting stage of the disease, it almost invariably progresses to a degenerative stage where chronic demyelination leads to axonal loss and permanent functional decline (Nave and Trapp, 2008), resulting in major disability and a 5-10 year reduction of life expectancy.

The cause of MS is not currently known, but likely represents a complex interaction of environmental circumstance and genetic predisposition, as both environmental and hereditary risk factors have been identified. Although the pathology of MS has been extensively studied, the disease mechanisms also remain elusive. This may in part be due to the intrinsic heterogeneity of the disease between individuals and between lesions within a single individual. However, regardless of these diverse pathological mechanisms, a common feature is failure of remyelination resulting in neurodegeneration. 
Primary demyelination is also a feature of neurological disorders including traumatic spinal cord injury and ischemic disease. It is likely that in both cases primary demyelination is followed by remyelination (albeit occurring at a rate that is age dependent). Whether there is persistent demyelination leading to axonal degeneration in either situation is unclear and in our view unlikely.

\subsection{Experimental models of demyelination}

In order to study the mechanisms of remyelination, the progression of inflammatory demyelinating disease and the potential for remyelination enhancement via therapeutic interventions, various experimental models have been developed. Most of these models are based either on toxin induced demyelination, or on immune induced inflammation with variable degrees of demyelination.

Toxin induced demyelination can be achieved systemically or focally (reviewed in Blakemore and Franklin, 2008). Focally induced toxic demyelination has proven an invaluable tool for studying the biology of the remyelination process. It is usually achieved by microinjecting ethidium bromide or lysolecithin into large white matter tracts of rodents. This creates local reproducible lesions, which undergo synchronous demyelination and remyelination. These are sometimes described as non-inflammatory models of demyelination; however, this is incorrect since, as with all injury models, they trigger an innate immune response, and the lysolecithin model also features a small involvement of adaptive immune cells. Such lesions are invaluable for dissecting different aspects of the remyelination process and how it responds to perturbations. However, these lesions remyelinate very efficiently, and although remyelination can be slowed by using aged animals (see below), it always proceeds to completion.

Systemically-delivered toxin-induced demyelination by oral administration of cuprizone is an alternative toxin model. The basic mode of action of cuprizone, a copper chelator, is presumed to be inhibition of oxidative phosphorylation. The reasons for its selectivity to particular regions of white matter is unknown, and it is presumed to influence other cells and processes in the body. This model is dependent on the species and strain of the animal used, 
the dosage of cuprizone, and the administration regimen. Repeat exposure can result in a model of chronic demyelination in which the acute inflammatory response is much subsided (Mason et al, 2004), a feature which together with the ease of administration makes it a popular although not necessarily optimum model.

The second group of demyelination models aim to mimic the immunopathogenesis of MS, rather than isolate the neurobiology of the regenerative response to demyelination. The main model in this group is experimental allergic/autoimmune encephalomyelitis (EAE), although valuable viral models also exist (e.g. Theiler's Murine Encephalomyelitis Virus). The basis of EAE is to induce an adaptive immune response to myelin, and this is done by immunization of the animal with myelin, or myelin proteins with the addition of Complete Freund's Adjuvant (CFA). This creates lesions that partially resemble those of MS. Many versions of EAE exist, some developed to specifically mimic certain aspects of MS (e.g. relapsing - remitting EAE, secondary progressive EAE). Although helpful in testing therapeutic interventions that modulate the maladaptive immune driver of disease, EAE models are not helpful in studying remyelination perse.

All these models have led to important discoveries and therapeutic developments (see below). However, it is often highlighted that species differences may lead to setbacks (although this is perhaps more true of immune cells than those of the CNS). Recently an interesting new experimental model has been developed based on use of a humanized mouse. Goldman and colleagues have generated mice completely myelinated by human oligodendrocytes and populated by human OPCs by transplanting human neural progenitor cells into neonatal mice (reviewed in Goldman et al, 2015). It has been proposed, that inducing demyelination in these mice would enable direct observation and experimental perturbation of human OPC mediated remyelination (Dietz et al, 2016). 


\section{Failure of remyelination}

\subsection{Why does remyelination fail?}

As well as disease specific reasons for remyelination failure (see below), the efficiency of the process is dependent on a host of generic (non disease specific) characteristics (Franklin and ffrench-Constant, 2008) like genetic background (Bieber et al, 2005), age (Shields et al, 1999) and gender (Li et al, 2006). Of these factors, age seems to be the most influential, and the most important for the progression of MS (Confavreux and Vukusic, 2006). All regenerative processes decrease with age, largely due to decreased function of adult somatic stem and progenitor cells (Sousounis et al, 2014), and remyelination is no exception. Both recruitment and differentiation phases of remyelination are slower in aged animals (Sim et al, 2002).

\subsection{At what stage does remyelination fail?}

In order for efficient remyelination to occur, activated OPCs must be recruited into the lesion and differentiate into myelinating oligodendrocytes. Failure at any point of this progression will result in a delay or arrest in remyelination. Numerous studies have attempted to elucidate the crucial point at which the process fails.

It is conceivable that remyelination would fail due to an age-associated decline in the numbers of adult OPCs. However, there is no good evidence to support this and the density of OPCs appears to remain stable throughout adult life (e.g. Sim et al. 2002).

A second possible reason for remyelination failure is that there is a failure of recruitment. This possibility is illustrated by the existence of MS lesions completely devoid of OPCs (Boyd et al, 2013) which is perhaps related to the presence of antibodies against the OPC antigen NG2 (Niehaus et al, 2000). Aged OPCs are recruited more slowly into lesions, possibly because they take more time to respond to growth factors and are less responsive to migration cues (Sim et al, 2002). The lesion size will also influence the time it requires for OPC recruitment, especially if they are all recruited from outside the lesion boundary (Chari et al, 2003).

However, though undoubtedly affected by ageing, at least in rodents failure of recruitment does not seem to be the rate limiting step of remyelination, as augmentation of recruitment 
into lesions in aged animals does not cause an improvement of the rate of remyelination (Woodruff et al, 2004). This study points to the possibility that OPC differentiation is the rate limiting step of remyelination with ageing - a hypothesis further strengthened by the existence of chronic MS lesions with OPCs and pre-oligodendrocytes seemingly unable to differentiate or myelinate (Chang et al, 2002; Kuhlmann et al, 2008). Due to this, many studies aiming to find a therapeutic target enhancing remyelination have concentrated on promoting OPC differentiation.

A recent hypothesis based on observations on human OPCs (discussed in Dietz et al, 2016) proposes that OPC differentiation efficiency depends on OPC density in the lesioned area. It has been noticed, that transplanted human OPCs tend to myelinate the axons of shiverer mice efficiently only once they reach a density of $>30000$ cells $/ \mathrm{mm}^{2}$. As density dependent differentiation has been described in vitro (Rosenberg et al, 2008) and a mechanism for OPCs sensing their local density has been proposed (Hughes et al, 2013), it is a possible mechanism of differentiation regulation. The authors propose a lower limit of OPC density of 10000 cells/ $\mathrm{mm}^{2}$ needed for differentiation to continue, based on OPC densities in normal adult white matter, periplaque regions and in regions of chronic demyelination. If this is the case, then experimental rodent models of remyelination almost never fall short of this limit, therefore density is never the rate limiting step in those models. Though not directly proven, this model is interesting as it functionally links the recruitment and differentiation phases of remyelination.

\subsection{Remyelination failure: intrinsic properties of remyelinating cells vs. extrinsic properties of the environment}

Regardless of the point at which remyelination fails, the failure of this process can always be traced to intrinsic changes within the OPC or extrinsic disturbances within the environment. Though a clear distinction between the two is difficult, it is a helpful framework with which to discuss remyelination failure. As adult stem cells show a deregulated epigenetic and transcriptional profile with ageing (Chambers et al, 2007; Liu et al, 2013), we can expect a similar process to be going on within the adult OPC. Indeed, changes within the OPC itself have been documented - aged OPCs transplanted into a lesion environment show a slower 
recruitment compared to younger controls (Chiari et al, 2003) and in older mice OPCs are more likely to differentiate into astrocytes in lesions (Doucette et al, 2010). Moreover, epigenetic dysregulation in aged OPCs has also been observed (Shen et al, 2008). In aged OPCs, insufficient recruitment of HDACs (histone deacetylases) to promoter regions of differentiation inhibitors like Hes5 leaves them active and stalls differentiation. As well as intrinsic disturbances, studies have identified a myriad of extrinsic sources which might contribute to remyelination failure (van Wijngaarden and Franklin, 2013). This is often a consequence of the presence of inhibiting factors within the lesion, or the absence of essential promoting factors that are normally present within the remyelinating environment.

\section{Dysregulation of the innate immune response}

The innate immune response is crucial for efficient remyelination (reviewed in McMurran et al, 2016; Miron and Franklin, 2014). Following a demyelinating injury, microglia and peripheral macrophages migrate into the lesion attracted by factors released by damaged cells. They phagocytose myelin debris and secrete factors stimulating OPC recruitment and differentiation. With ageing, both of these functions are reduced (Miron et al, 2013; Natrajan et al, 2015; Ruckh et al, 2012). This stalls remyelination in a twofold manner: first, by reducing the amount of factors directly regulating OPC function and, second, by reducing the efficiency of phagocytic removal of myelin debris, which inhibits differentiation (Kotter et al, 2005). These effects can be experimentally mimicked by reducing macrophage number or activation, or by injecting myelin debris into a lesion (Kotter et al, 2001; Kotter et al, 2006).

\section{Dysregulation of the migratory cues}

Both in development and in remyelination, OPCs use migratory cues to find the area they are to (re)populate. For example, class 3 semaphorins have been described to regulate developmental OPC migration in an antagonistic fashion - SEMA3A serving as a repellent and SEMA3F as an attractant (Spassky et al 2002). Both were found to be expressed in MS brains and in response to experimental demyelination (Williams et al, 2007). The imbalance of these factors could be the reason for remyelination failure, especially in MS lesions devoid of OPCS (Boyd et al, 2013). In addition to these guidance functions, SEMA3A inhibits OPC differentiation 
in vitro and in CCP lesions (Syed et al, 2011), further implicating overexpression of this molecule as a potential cause of remyelination failure.

Inhibitory extracellular matrix (ECM) molecules within the lesion

The adult CNS is devoid of a conventional extracellular matrix; however, ECM molecules are expressed in development and re-expressed following CNS insults (Colognato and Tzvetanova, 2011; Zhao et al, 2009). Glycosaminoglycans (GAGc) are amongst the re-expressed ECM molecules within lesions. Two types of GAGs are implicated in inhibiting remyelination: hyaluronans and chondroitin sulfate proteoglycans (CSPGs). Hyalouronan is found accumulating in spinal cord injury and MS lesions (Back et al, 2005). In response to demyelination, high molecular weight hyaluronan is synthesized by astrocytes in MS and EAE. Oligodendrocyteexpressed hyaluronidases attempt to degrade it, and the products of this degradation interact with the TLR2 receptors on oligodendroglia leading to OPC maturation arrest (Preston et al, 2013; Sloane et al, 2010). CSPGs, also found in MS lesions (Sobel and Ahmed, 2001; van Horssen et al, 2006) have similarly been shown to arrest OPC process outgrowth and remyelination through interacting with the PTPo receptor (Pendelton et al, 2013). Importantly, this inhibition can be reduced by administration of chondroitinase ABC (Lau et al, 2012; Pendelton et al, 2013) or by inhibiting CSPG synthesis (Keough et al, 2016), proving that the CSPG mediated differentiation block was reversible.

\section{Axon-oligodendrocyte interactions}

It seems likely that the longer an axon remains demyelinated, the more vulnerable to degeneration it becomes (Franklin et al, 2012). Demyelinated axons express PSA-NCAM on their surface, a neural cell adhesion molecule that must become downregulated if efficient myelination is to occur (Charles et al, 2000; Fewou et al, 2007). PSA-NCAM is expressed on the surface of $11-19 \%$ of demyelinated axons in MS lesions (Charles et al, 2002), potentially inhibiting their remyelination.

Recently, it has also been shown that in order to remyelinate efficiently, axons must be electrically active and release glutamate. Blocking neuronal activity, axonal vesicular release or 
AMPA receptors in demyelinated lesions reduces remyelination and increases the number of undifferentiated OPCs within lesions (Gautier et al, 2015).

\subsection{Efficient remyelination - the role of cell signaling pathways}

Remyelination failure often involves the dysregulation of molecular pathways essential for oligodendrocyte differentiation and myelination. These pathways integrate extrinsic information from the extracellular signaling molecules with the intrinsic state of the cell, to drive, permit or inhibit efficient remyelination. For this reason, many have been researched and targeted for therapeutic enhancement of remyelination.

When cell signaling pathways involved in remyelination control, such as the Wnt pathway (reviewed in Guo et al, 2015), the Notch pathway (Brosnan and John, 2008) or the BMP pathway (Grinspan et al, 2015) began to be discovered, it was hoped that simple inhibition or enhancement of a given pathway would enhance remyelination in disease states (Fancy et al, 2010). Increasingly however, the complexity, crosstalk and non-binary nature of these signals is beginning to be recognized, and the reality is much more challenging. A summary of the role of Wnt in OPC differentiation illustrates this.

The canonical Wnt signaling pathway is highly conserved and crucial for the specification, differentiation and growth of many cells (van Amerongen and Nusse, 2009). In mammals, extracellular Wnt ligands bind to Frizzled receptors and their co-receptors, and through the LRP5 and LRP6 proteins act to stabilize intracellular $\beta$-catenin (which, in the absence of Wnt signal is complexed and targeted for proteasomal degradation). $\beta$-catenin can either remain attached to the cell membrane, or translocate into the nucleus and interact with TCF/LEF transcription factors to stimulate gene expression.

Strong evidence emerged to suggest that canonical Wnt signaling inhibits OPC differentiation in remyelination, and therefore inhibiting the pathway would likely enhance remyelination. An in situ based transcription factor screen of the lysolecithin spinal cord lesion revealed expression of Tcf4 in Olig2 positive cells during remyelination, implicating Wnt pathway involvement. Indeed, constitutive activation of $\beta$-catenin in Olig2cre/DA-Cat mice delayed remyelination of lysolecithin lesions (Fancy et al, 2009), while Axin2 (one of $\beta$-catenin 
degradation complex factors) double knockout mice also showed delayed remyelination in comparison to wild type controls, despite exhibiting normal OPC recruitment (Fancy et al, 2011b). Moreover, treatment of wild type mice with XAV939 - an Axin2 stabilizer (and thereby a promoter of $\beta$-catenin degradation), significantly increased the rate of OPC differentiation within lysolecithin lesions (Fancy et al, 2011b). These studies, together with similar findings in developmental myelination and reports of increased Wnt pathway gene and protein expression in the context of MS lesions (Han et al, 2008; Lock et al, 2002) indicate inhibitory effects of high Wnt tone on OPC differentiation.

However, addition of Wnt stimulates oligodendrocyte maturation in culture, while overexpression of nucleus-located $\beta$-catenin increases proteolipid protein promoter activity (Tawk et al, 2011). Furthermore, remyelination is stalled in Tcf4 null mice (Ye et al, 2009).

In an attempt to reconcile these seemingly contradictory results, a model where Tcf4 triggered opposing actions depending on the whether it was coupled with $\beta$-catenin or HDAC1/2 has been proposed - as histone deacetylases were found to compete with $\beta$-catenin for binding to Tcf4 (Ye et al, 2009). Alternatively, it has been hypothesized that Tcf4 activation is not necessarily always coupled to Wnt/ $\beta$-catenin signaling and increased Tcf4 activation in OPCs failing to differentiate could be a secondary effect rather than a cause of differentiation failure in the first place (Hammond et al, 2015). A generalized model of Wnt signaling in remyelination has been proposed by Guo and colleagues, postulating that the outcome of Wnt signaling depends on the differentiation stage of the cell. The transition of OPC to immature oligodendrocyte is hypothesized to require a low level Wnt tone, and so a pathologically high Wnt tone will cause differentiation inhibition (Fancy et al, 2014). Meanwhile further maturation to myelinating oligodendrocyte is proposed to require $\beta$-catenin-independent Tcf4 activation, uncoupling Tcf4 action and expression from Wnt tone (Guo et al, 2015).

To further complicate matters, non-canonical Wnt pathways could also play a role in myelination, and Wnt signaling has been proven to crosstalk with the Akt/mTOR pathway in the oligodendrocyte lineage (Tyler et al, 2009) and doubtless with many more. 
As with the Wnt pathway, many other critical signaling pathways have been discovered to modulate remyelination in a diverse, context dependent manner (Gaesser and Fyffe-Maricich, 2016), and although a predominant effect is often present, such pleiotropism presents challenges for developing therapeutic interventions.

\section{Enhancing endogenous stem cells - current and future therapies}

In establishing effective therapies for myelin disease, two strategies have been pursued: 1) enhancing endogenous remyelination and 2) providing exogenous myelinating cells by cell transplantation. In the context of intrinsic disorders of myelin assembly or metabolism, providing an exogenous source of myelination is the logical approach. However, in the case of acquired demyelinating disorders, remyelination failure is likely more due to pathological changes of the lesion environment, than a failure of the remyelinating cells themselves. Indeed, myelinogenic cells often fail to survive or sufficiently differentiate when transplanted into demyelinated lesion environments (reviewed by Pluchino et al, 2004). Crucially, intrinsic changes in failing OPCs have been proven to be, in principle, reversible, and could be overcome by environment modification (Ruckh et al, 2012). Therefore, it makes sense to attempt enhancement of endogenous remyelination when considering therapies for acquired demyelinating disorders.

Although the endogenous enhancement approach circumvents many problems related with cell transplantation (such as optimizing cell delivery, considering the ethics, immunological implications and sustainability of the cell source, etc.), it comes with its own challenges. For any remyelination enhancing therapy to be effective, it must be delivered efficiently to the site of action (i.e. past the blood brain barrier), act specifically on the cells of interest and reliably trigger the appropriate response. As with all remyelinating therapies, an objective, standardized and relatively non-invasive way of assessing outcomes must be available in order to compare and evaluate outcomes of proposed treatments against each other and the current clinical gold standard. 


\subsection{Rejuvenation as an approach to enhance remyelination}

Ageing is one of the crucial contributory factors of remyelination failure. Experiments using heterochronic parabiosis of old and young animals have proven that lesions in old animals can be efficiently remyelinated by old OPCs, provided they are exposed to a young environment (Ruckh et al, 2012). These experiments further demonstrated that the rejuvenation effects were in part due to increased myelin debris phagocytizing efficiency of young macrophages and that serum-derived factors from the young circulation also contribute to the rejuvenation effect.

Much recent research has centered on the hallmarks of ageing and interventions designed to reverse or slow it (Lopez-Otin et al, 2013). It seems likely that ageing will affect the inherent behavior of adult OPCs and indeed, age related epigenetic dysregulation of OPCs has been demonstrated (Shen et al, 2008).

Physiological interventions resulting in decreased anabolic signaling (like dietary restriction and endurance training) or drugs that mimic such interventions, extend lifespan in animals (Fontana et al, 2010; Harrison et al, 2009), and slow the progression of numerous age related disease processes including neurodegeneration (Duan and Ross, 2010). Given that these strategies have been demonstrated to enhance the function of other adult stem cells (Cerletti et al,2012; Chen et al 2003; Yilmaz et al, 2012) it seems very likely that these interventions will be beneficial in enhancing remyelination.

\subsection{The translational pathway - from bench to bedside}

Many remyelination enhancing drugs currently in pre-clinical testing or clinical trials are the result of a systematic search for therapeutic targets. The approach is based on the identification of non-redundant pathways and critical downstream effectors, augmentation or inhibition of which leads to enhancement of remyelination. These pathways, or their modulators are often identified through a screen based study. If the validation data are promising, the finding is further tested in various experimental disease models, often where the translatability of the modulating compounds, the routes of delivery and potential side effects 
are beginning to be explored. Finally, if animal studies show a robust effect, the experimental compound is taken to clinical trials to assess the safety, tolerability and efficacy in humans.

\section{Lingo1 inhibition}

In search for pathways inhibiting axon regeneration, a receptor complex inhibiting neurite outgrowth in response to myelin debris was described. This complex, composed of the Nogo66 and p75NTR receptors, was found to inhibit neurite outgrowth through RhoA inhibition (Fournier et al, 2001). In an attempt to identify the NgR1 complex activators by screening uncharacterized, CNS-specific proteins, the LRR and Ig domain-containing, Nogo Receptor interacting protein, LINGO-1, was found (Mi et al, 2004). Later, this protein was shown to inhibit oligodendrocyte differentiation via homophilic extracellular interactions and by blocking activation of ErbB2 (Mi et al, 2005; Lee et al, 2014).

Lingo1 is expressed in the CNS and its inhibition using multiple approaches in culture enhances OPC differentiation (Mi et al, 2005). Lingo1 inhibition was also found to enhance dorsal root ganglion (DRG) co-culture myelination (Lee et al, 2007). Furthermore, OPCs from Lingo1 knockout animals exhibited enhanced differentiation in vitro (Mi et al, 2005).

In animal studies, Lingo inhibition was found to enhance remyelination in lysolecithin and cuprizone models of demyelination. Lingo1 knockout mice were found to exhibit resistance to EAE development, while inhibiting Lingo1 in wild type EAE mice, mitigated disease severity leading to improved regeneration and function (Mi et al, 2007; Mi et al 2009). However, increased remyelination efficiency in Lingo1 knock-out mice has not been reported neither has there been a systematic analysis of Lingo1 expression in oligodendrocyte lineage cells in the various models of CNS demyelination and remyelination.

Based on the pre-clinical data, BIIB033, a fully humanized IgG1 monoclonal anti Lingo1 antibody was developed. The antibody was found to be safe and well tolerated in Phase I clinical trials, and two phase II trials were set up. The first, a trial of anti Lingo1 therapy in optic neuritis, failed to reach its primary endpoint (retinal fiber thickness preservation), although the therapy did show improvement in latency of Visually Evoked Potentials, which was one of the 
trials secondary endpoints (NCT01721161). The second study, a Phase II BlIB033 trial in relapsing-remitting MS (NCT018641487) was recently reported to have missed its primary endpoint.

\section{RXR agonists}

Retinoid X nuclear receptors (RXRs) and especially RXR $\gamma$, were found to have increased levels of expression in transcriptional profiling of remyelinating focal toxic lesions, clustering together with other genes related to oligodendrocyte differentiation. Upon further analysis, it was revealed that pharmacologically antagonizing RXR $\gamma$ inhibited OPC differentiation and myelination in vitro. Furthermore, stimulation of RXR $\gamma$ through administration of the RXR agonist, 9cis retinoic acid (9cRA) accelerated remyelination in aged animals (Huang et al, 2011).Subsequently, it was shown that activation of the VDR-RXR heterodimer enhances OPC differentiation in vitro, and pharmacologically blocking VDR impaired remyelination, and partially abrogated the 9cisRA effect on OPC differentiation in vitro (de la Fuente et al, 2015). These findings underscore the importance of RXR signaling in the regenerative phase of MS, as well as the well documented role of vitamin D in disease susceptibility (Burton and Costello, 2015).

However, RXR signaling in the CNS is not restricted only to oligodendrocyte lineage cells. A recent study by Natrajan et al. (2015) has shown that RXR also influences macrophages in the CNS. Previously it had been established that aged macrophages and monocytes within the lesion are not as efficient in myelin debris phagocytosis as young monocytes (Ruckh et al., 2012; see above). When the transcriptional profile of these cells was compared to young ones, the expression levels of genes related to the RXR pathway were found to be significantly decreased. Furthermore, when RXR signaling was stimulated in these cells, through treatment with bexarotene (an RXR agonist), these cells displayed a rejuvenated phenotype, which much improved myelin clearance. As predicted by these experiments, when animals with monocyte specific RXR $\alpha$ knockout were subject to a focal demyelinative lesion, remyelination was delayed, most probably due to a delayed clearance of myelin debris (Natrajan et al, 2015). This study provided a second, indirect, oligodendroglia independent way in which RXR signaling 
stimulation could augment remyelination. On top of this, stimulating RXR in EAE was shown to improve EAE symptoms, via T cell modulation (Chandraratna et al. 2016).

As RXR agonists are extensively studied for therapeutic use in cancer and metabolic disease, with one, bexarotene, already in clinical use, RXR signaling seems to be a very attractive therapeutic target for enhancing remyelination, especially due to its multi-targeted beneficial actions. No clinical trials have been publicized to date, but experimental evidence makes a clinical trial very likely in the foreseeable future.

\subsection{Drug repurposing for remyelination}

An alternative way of finding interventions enhancing remyelination is to screen libraries of already existent FDA approved compounds or track comorbid patient data for potential remyelinating effects of drugs already in clinical use. This approach has the advantage of circumventing the need for safety evaluation of the treatment, and greatly facilitates the introduction into clinical trials. However, this often means the mechanisms of action for the intervention are unclear at the time of the discovery, and sometimes these compounds turn out to act in ways other than enhancing remyelination.

One interesting example of this is fingolimod (FT7720). Fingolimod was the first approved oral disease modifying drug for relapsing remitting MS (Brinkmann et al, 2010). It was assumed to act though attenuating inflammation in MS, as it was shown to inhibit lymphocyte dissemination from secondary lymphoid organs in EAE, through chronic binding and irreversible internalization of sphingosine-1-phosphate receptors (Kataoka et al, 2005; Papadopoulos et al, 2010). However, further experiments also revealed its unexpected cytoprotective effects on oligodendroglia. Fingolimod was found to protect oligodendrocytes in culture and in toxic lesions (Miron et al, 2008; Kim et al, 2011) and to enhance remyelination in cerebellar slice cultures (Moyon et al , 2010). In light of these findings, and the fact that fingolimod slows brain atrophy in RRMS (Barkhof et al, 2014), a phase III clinical trial of fingolimod on primary progressive MS was set up. Unfortunately, it failed to find a therapeutic effect (Lublin et al, 
2016). However, the established therapeutic benefits of fingolimod may well be due to its action on oligodendroglia as well due to its immunomodulatory properties.

A systematic approach was recently employed in a large scale phenotypic screen of drugs with a proven clinical safety profile. These compounds were tested on mouse epiblast stem cell derived OPCs, and screened for extent of differentiation enhancement in vitro, by image quantification of myelin protein expression. This screen resulted in the identification of many compounds including clobetasole and miconasole - both in current clinical use for other indications. Follow-up studies confirmed differentiation enhancement by these drugs in organotypic cerebellar slice cultures, developmental myelination, and in a toxin demyelination model, and proposed a mechanism of action for both drugs, promoting them as likely targets for clinical studies (Najm et al, 2015).

Another high-throughput screen, conducted on primary rat optic nerve derived OPC cultures similarly aimed to find OPC differentiation enhancing drugs by measuring MBP expression in cultured cells treated with around 100000 different active compounds (Deschmukh et al, 2013). Benztropine, a muscarinic antagonist used clinically in Parkinson's Disease treatment, was found among the most effective differentiation accelerating substances, and its effects were confirmed in EAE and cuprizone animal models. Antimuscarinic compounds were also implicated as myelination enhancers in a novel screening approach using micropillar arrays, engineered specifically to optimize high throughput OPC differentiation screens (Mei et al, 2014). Here, the authors validated the efficacy of Clemastine, an antihistamine with antimuscarinic properties, and confirmed that it promoted remyelination in the rodent lysolecithin model. Based on convergent evidence from both, FDA approved antimuscarinic agents will most likely be considered for clinical trials in the near future.

\subsection{Autoantibodies - the solution from within}

An interesting approach to enhancing remyelination is through the use of autoantibodies. These naturally occurring antibodies, present in the serum in the absence of stimulation by foreign antigens, have been found in almost all vertebrate species. First reported in 1966 
(Boyden, 1966), antibodies are regarded as systemic surveillance molecules that have been found to prevent autoimmunity by enforcing B-cell central tolerance induction (Nguyen et al 2015). In contrast to conventional antibodies, autoantibodies bind to diverse antigens with low affinity and exhibit a short half-life.

Remyelination enhancing autoantibodies were discovered by accident, when antibodies against myelin components were found to enhance remyelination in TMV infected animals (Lang et al 1984, Rodriguez et al 1987) rather than worsen the disease. Following from this, autoantibodies to oligodendrocytes and myelin were found in human serum samples. After the confirmation of remyelination enhancement in vivo by 2 of the discovered autoantibodies, the var sequence of one of them was cloned to generate a humanized monoclonal antibody rHIgM22 (Mitsunaga et al, 2002; Warrington et al, 2007). The antibody was found to act by inhibiting apoptosis and oligodendrocyte differentiation as part of an extracellular complex containing PDGFr $\alpha, \alpha \mathrm{V} \beta 3$ integrin and Lyn kinase (Watzlawik et al, 2010). rHIgM22 promoted survival and proliferation of OPCs in vitro, but only in mixed brain cultures and not in pure OPC cultures- underscoring the importance of factors released by other glial cells in the antibody complex activation (Watzlawik et al, 2013).

Phase I trials confirmed the predictions of these antibodies being very safe and well tolerated. The presence of $A b$ at the lesion site (and hence their efficient crossing of the bloodbrain barrier) was confirmed by finding the Ab in CSF samples of every patient in the trial (NCT01803867). Following the success of safety trials, phase II trials are highly anticipated, especially as $\mathrm{rHIg} 22$ is one of the few clinically trialed remyelination enhancers that seem to act by promoting OPC survival and enhancing proliferation, rather than supporting differentiation.

\section{Concluding remarks}

Remyelination is a remarkable example of CNS regeneration. Studying the biology of this process, along with the conditions in which it fails, has led to important discoveries that are increasingly likely to become translatable into disease modifying therapies. Crucially, in 
acquired demyelinating disorders, it seems that remyelination failure is not insurmountable, and enhancing endogenous remyelination by therapeutic intervention may soon be achievable. A continued effort to identify the essential pathways and downstream effectors of the OPC differentiation process is needed to increase the range of potential therapeutic targets.

Although we now know more than ever before about remyelination, questions still remain. Is remyelination as robust as developmental myelination in terms of supporting long term axonal integrity? Can remyelination capacity be irreversibly exhausted? Is Schwann cell remyelination in the CNS a desired phenomenon? These and other questions will need to be answered, before we can fully comprehend the nature and harness the function of endogenous remyelination.

\section{Acknowledgments:}

We would like to thank Ludiovica Di Canio, Bjoern Neumann and Alerie Guzman de la Fuente for help in reviewing the content and form of this chapter. 


\section{References}

Barkhof F, de Jong R, Sfikas N, de Vera A, Francis G, Cohen J, et al. The influence of patient demographics, disease characteristics and treatment on brain volume loss in Trial Assessing Injectable Interferon vs FTY720 Oral in Relapsing-Remitting Multiple Sclerosis (TRANSFORMS), a phase 3 study of fingolimod in multiple sclerosis. Mult Scler. SAGE Publications; 2014 Nov;20(13):1704-13.

Bergles DE, Richardson WD. Oligodendrocyte Development and Plasticity. Cold Spring Harb Perspect Biol. 2016 Feb 1;8(2):a020453-28.

Bieber AJ. Genetic analysis of CNS remyelination. Curr Top Microbiol Immunol 2008;318:177-192.

Blakemore WF, Franklin RJM. Remyelination in experimental models of toxin-induced demyelination. Curr Top Microbiol Immunol. 2008;318:193-212.

Boyd A, Zhang H, Williams A. Insufficient OPC migration into demyelinated lesions is a cause of poor remyelination in MS and mouse models. Acta Neuropathologica. Springer-Verlag; 2013 Jun;125(6):841-59.

Boyden SV. Natural antibodies and the immune response. Adv Immunol. 1966;5:1-28.

Brinkmann V, Billich A, Baumruker T, Heining P, Schmouder R, Francis G, et al. Fingolimod (FTY720): discovery and development of an oral drug to treat multiple sclerosis. Nature Reviews Drug Discovery. Nature Publishing Group; 2010 Dec;9(12):955-5.

Brosnan CF, John GR. Revisiting Notch in remyelination of multiple sclerosis lesions. Journal of Clinical Investigation. American Society for Clinical Investigation; 2008 Dec 22;119(1):10-3.

Burton JM, Costello FE. Vitamin D in Multiple Sclerosis and Central Nervous System Demyelinating Disease-A Review. Journal of Neuro-Ophthalmology. 2015 Jun;35(2):194200.

Calzà L, Fernandez M, Giuliani A, D'Intino G, Pirondi S, Sivilia S, et al. Thyroid hormone and remyelination in adult central nervous system: A lesson from an inflammatory-demyelinating disease. 2005. pp. 339-46. 
Cerletti M, Jang YC, Finley LWS, Haigis MC, Wagers AJ. Short-term calorie restriction enhances skeletal muscle stem cell function. Cell Stem Cell. 2012 May 4;10(5):515-9.

Chambers SM, Shaw CA, Gatza C, Fisk CJ, Donehower LA, Goodell MA. Aging hematopoietic stem cells decline in function and exhibit epigenetic dysregulation. Dillin A, editor. PLoS Biol. Public Library of Science; 2007 Aug;5(8):e201.

Chandraratna RA, Noelle RJ, Nowak EC. Treatment with retinoid X receptor agonist IRX4204 ameliorates experimental autoimmune encephalomyelitis. Am J Transl Res. e-Century Publishing Corporation; 2016;8(2):1016-26.

Chang A, Tourtellotte WW, Rudick R, Trapp BD. Premyelinating oligodendrocytes in chronic lesions of multiple sclerosis. N Engl J Med. Massachusetts Medical Society; 2002 Jan $17 ; 346(3): 165-73$.

Chari DM, Crang AJ, Blakemore WF. Decline in rate of colonization of oligodendrocyte progenitor cell (OPC)-depleted tissue by adult OPCs with age. J Neuropathol Exp Neurol. 2003 Sep;62(9):908-16.

Charles P, Hernandez MP, Stankoff B, Aigrot MS, Colin C, Rougon G, et al. Negative regulation of central nervous system myelination by polysialylated-neural cell adhesion molecule. Proc Natl Acad Sci USA. National Acad Sciences; 2000 Jun 20;97(13):7585-90.

Charles P, Reynolds R, Seilhean D, Rougon G, Aigrot MS, Niezgoda A, et al. Re-expression of PSANCAM by demyelinated axons: an inhibitor of remyelination in multiple sclerosis? Brain. 2002 Sep;125(Pt 9):1972-9.

Chen J, Astle CM, Harrison DE. Hematopoietic senescence is postponed and hematopoietic stem cell function is enhanced by dietary restriction. Exp Hematol. 2003 Nov;31(11):1097-103.

Chong SYC, Rosenberg SS, Fancy SPJ, Zhao C, Shen Y-AA, Hahn AT, et al. Neurite outgrowth inhibitor Nogo-A establishes spatial segregation and extent of oligodendrocyte myelination. Proc Natl Acad Sci USA. National Acad Sciences; 2012 Jan 24;109(4):1299-304.

Colognato H, Tzvetanova ID. Glia unglued: How signals from the extracellular matrix regulate the development of myelinating glia. Devel Neurobio. 2011 Oct 11;71(11):924-55. 
Compston A, Coles A. Multiple sclerosis. The Lancet. 2008;372(9648):1502-17.

Confavreux C, Vukusic S. Age at disability milestones in multiple sclerosis. Brain. Oxford University Press; 2006 Mar;129(Pt 3):595-605.

Crawford AH, Stockley JH, Tripathi RB, Richardson WD, Franklin RJM. Oligodendrocyte progenitors: Adult stem cells of the central nervous system? Exp Neurol. 2014 Oct; 260:505.

Deshmukh VA, Tardif V, Lyssiotis CA, Green CC, Kerman B, Kim HJ, et al. A regenerative approach to the treatment of multiple sclerosis. Nature. Nature Publishing Group, a division of Macmillan Publishers Limited. All Rights Reserved; 2013 Oct 9;502(7471):327-32.

Dietz KC, Polanco JJ, Pol SU, Sim FJ. Targeting human oligodendrocyte progenitors for myelin repair. Exp Neurol. 2016 Sep;283:489-500.

Dimou L, Gallo V. NG2-glia and their functions in the central nervous system. Götz M, Gallo V, editors. Glia. 2015 Aug;63(8):1429-51.

Doucette JR, Jiao R, Nazarali AJ. Age-related and cuprizone-induced changes in myelin and transcription factor gene expression and in oligodendrocyte cell densities in the rostral corpus callosum of mice. Cell Mol Neurobiol. 2010 May;30(4):607-29.

Duan W, Ross CA. Potential therapeutic targets for neurodegenerative diseases: lessons learned from calorie restriction. CDT. 2010 Oct;11(10):1281-92.

Duncan ID, Brower A, Kondo Y, Curlee JF, Schultz RD. Extensive remyelination of the CNS leads to functional recovery. Proc Natl Acad Sci USA. National Acad Sciences; 2009 Apr $21 ; 106(16): 6832-6$.

Duncan ID, Radcliff AB. Inherited and acquired disorders of myelin: The underlying myelin pathology. Exp Neurol. Elsevier Inc; 2016 Sep 1;283(Part B):452-75.

Emery B, Lu QR. Transcriptional and epigenetic regulation of oligodendrocyte development and myelination in the Central Nervous System. Cold Spring Harb Perspect Biol. Cold Spring Harbor Lab; 2015 Sep;7(9):a020461 
Fancy SPJ, Baranzini SE, Zhao C, Yuk D-I, Irvine K-A, Kaing S, et al. Dysregulation of the Wnt pathway inhibits timely myelination and remyelination in the mammalian CNS. Genes \& Development. Cold Spring Harbor Lab; 2009 Jul 1;23(13):1571-85.

Fancy SPJ, Chan JR, Baranzini SE, Franklin RJM, Rowitch DH. Myelin regeneration: a recapitulation of development? Annu Rev Neurosci. Annual Reviews; 2011;34(1):21-43.

Fancy SPJ, Harrington EP, Yuen TJ, Silbereis JC, Zhao C, Baranzini SE, et al. Axin2 as regulatory and therapeutic target in newborn brain injury and remyelination. Nat Neurosci. Nature Research; 2011 Jun 26;14(8):1009-16.

Fancy SPJ, Kotter MR, Harrington EP, Huang JK, Zhao C, Rowitch DH, et al. Overcoming remyelination failure in multiple sclerosis and other myelin disorders. Exp Neurol. 2010;225(1):18-23.

Fancy SPJ, Zhao C, Franklin RJM. Increased expression of Nkx2.2 and Olig2 identifies reactive oligodendrocyte progenitor cells responding to demyelination in the adult CNS. Mol Cell Neurosci. 2004 Nov;27(3):247-54.

Fancy SPJ, Harrington EP, Baranzini SE, Silbereis JC, Shiow LR, Yuen TJ, et al. Parallel states of pathological Wnt signaling in neonatal brain injury and colon cancer. Nat Neurosci. 2014 Mar $9 ; 17(4): 506-12$.

Felts PA, Baker TA, Smith KJ. Conduction in segmentally demyelinated mammalian central axons. Journal of Neuroscience. 1997 Oct 1;17(19):7267-77.

Fewou SN, Ramakrishnan H, Büssow H, Gieselmann V, Eckhardt M. Down-regulation of polysialic acid is required for efficient myelin formation. J Biol Chem. American Society for Biochemistry and Molecular Biology; 2007 Jun 1;282(22):16700-11.

Fietz SA, Lachmann R, Brandl H, Kircher M, Samusik N, Schröder R, et al. Transcriptomes of germinal zones of human and mouse fetal neocortex suggest a role of extracellular matrix in progenitor self-renewal. Proc Natl Acad Sci USA. National Acad Sciences; 2012 Jul $17 ; 109(29): 11836-41$. 
Fontana L, Partridge L, Longo VD. Extending healthy life span-from yeast to humans. Science. American Association for the Advancement of Science; 2010 Apr 16;328(5976):321-6.

Fournier AE, GrandPre T, Strittmatter SM. Identification of a receptor mediating Nogo-66 inhibition of axonal regeneration. Nature. Nature Publishing Group; 2001 Jan 18;409(6818):341-6.

Franklin RJM, Ffrench-Constant C, Edgar JM, Smith KJ. Neuroprotection and repair in multiple sclerosis. Nat Rev Neurol. 2012;8(11):624-34.

Franklin RJM, ffrench-Constant C. Remyelination in the CNS: from biology to therapy. Nat Rev Neurosci. 2008 Nov;9(11):839-55.

Fünfschilling U, Supplie LM, Mahad D, Boretius S, Saab AS, Edgar J, et al. Glycolytic oligodendrocytes maintain myelin and long-term axonal integrity. Nature. 2012 May 24;485(7399):517-21.

Gaesser JM, Fyffe-Maricich SL. Intracellular signaling pathway regulation of myelination and remyelination in the CNS. Exp Neurol. Elsevier Inc; 2016 Sep 1;283(Part B):501-11.

Gautier HOB, Evans KA, Volbracht K, James R, Sitnikov S, Lundgaard I, et al. Neuronal activity regulates remyelination via glutamate signalling to oligodendrocyte progenitors. Nat Commun. Nature Publishing Group; 2015 Oct 6;6:8518.

Giedd JN, Blumenthal J, Jeffries NO, Castellanos FX, Liu H, Zijdenbos A, et al. Brain development during childhood and adolescence: a longitudinal MRI study. Nat Neurosci. 1999 Oct;2(10):861-3.

Giraudon P, Vincent P, Vuaillat C, Verlaeten O, Cartier L, Marie-Cardine A, et al. Semaphorin CD100 from activated T lymphocytes induces process extension collapse in oligodendrocytes and death of immature neural cells. J Immunol. 2004 Jan 15;172(2):1246-55.

Goldman SA, Nedergaard M, Windrem MS. Modeling cognition and disease using human glial chimeric mice. Götz M, Gallo V, editors. Glia. 2015 Aug;63(8):1483-93.

Gregg C, Shikar V, Larsen P, Mak G, Chojnacki A, Yong VW, et al. White matter plasticity and enhanced remyelination in the maternal CNS. J Neurosci. Society for Neuroscience; 2007 Feb 
21;27(8):1812-23.

Griffiths I, Klugmann M, Anderson T, Yool D, Thomson C, Schwab MH, et al. Axonal swellings and degeneration in mice lacking the major proteolipid of myelin. Science. 1998 Jun 5;280(5369):1610-3.

Grinspan JB. Bone Morphogenetic Proteins: Inhibitors of Myelination in Development and Disease. Vitam Horm. Elsevier; 2015;99:195-222.

Guo F, Lang J, Sohn J, Hammond E, Chang M, Pleasure D. Canonical Wnt signaling in the oligodendroglial lineage--puzzles remain. Glia. 2015 Oct;63(10):1671-93.

Hammond E, Lang J, Maeda Y, Pleasure D, Angus-Hill M, Xu J, et al. The Wnt effector transcription factor 7-like 2 positively regulates oligodendrocyte differentiation in a manner independent of Wnt/ $\beta$-catenin signaling. J Neurosci. Society for Neuroscience; 2015 Mar 25;35(12):500722.

Han MH, Hwang S-I, Roy DB, Lundgren DH, Price JV, Ousman SS, et al. Proteomic analysis of active multiple sclerosis lesions reveals therapeutic targets. Nature. 2008 Feb 28;451(7182):107681.

Harrison DE, Strong R, Sharp ZD, Nelson JF, Astle CM, Flurkey K, et al. Rapamycin fed late in life extends lifespan in genetically heterogeneous mice. Nature. Nature Publishing Group; 2009 Jul 16;460(7253):392-5.

Hinks GL, Franklin RJ. Distinctive patterns of PDGF-A, FGF-2, IGF-I, and TGF-beta1 gene expression during remyelination of experimentally-induced spinal cord demyelination. Mol Cell Neurosci. 1999 Aug;14(2):153-68.

Horner P. Proliferation and differentiation of progenitor cells throughout the intact adult rat spinal cord. Journal of Neuroscience. 2000 Mar 15;20(6):2218-28.

Huang JK, Jarjour AA, Nait Oumesmar B, Kerninon C, Williams A, Krezel W, et al. Retinoid X receptor gamma signaling accelerates CNS remyelination. Nat Neurosci. 2011 Jan;14(1):4553. 
Hughes EG, Kang SH, Fukaya M, Bergles DE. Oligodendrocyte progenitors balance growth with self-repulsion to achieve homeostasis in the adult brain. Nat Neurosci. 2013 Jun;16(6):66876.

Jablonska B, Aguirre A, Raymond M, Szabo G, Kitabatake Y, Sailor KA, et al. Chordin-induced lineage plasticity of adult SVZ neuroblasts after demyelination. Nat Neurosci. Nature Research; 2010 May;13(5):541-50.

Jeffery ND, Blakemore WF. Locomotor deficits induced by experimental spinal cord demyelination are abolished by spontaneous remyelination. Brain. 1997 Jan;120 ( Pt 1):2737.

Kang SH, Fukaya M, Yang JK, Rothstein JD, Bergles DE. NG2+ CNS glial progenitors remain committed to the oligodendrocyte lineage in postnatal life and following neurodegeneration. Neuron. Elsevier; 2010 Nov 18;68(4):668-81

Kataoka H, Sugahara K, Shimano K, Teshima K, Koyama M, Fukunari A, et al. FTY720, sphingosine 1-phosphate receptor modulator, ameliorates experimental autoimmune encephalomyelitis by inhibition of T cell infiltration. Cell Mol Immunol. 2005 Dec;2(6):439-48.

Keough MB, Rogers JA, Zhang $P$, Jensen SK, Stephenson EL, Chen $T$, et al. An inhibitor of chondroitin sulfate proteoglycan synthesis promotes central nervous system remyelination. Nat Commun. Nature Publishing Group; 2016 Apr 26;7:11312

Kim HJ, Miron VE, Dukala D, Proia RL, Ludwin SK, Traka M, et al. Neurobiological effects of sphingosine 1-phosphate receptor modulation in the cuprizone model. FASEB J. Federation of American Societies for Experimental Biology; 2011 May;25(5):1509-18.

Kotter MR. Myelin Impairs CNS Remyelination by Inhibiting Oligodendrocyte Precursor Cell Differentiation. J Neurosci. Society for Neuroscience; 2006 Jan 4;26(1):328-32.

Kotter MR, Setzu A, Sim FJ, Van Rooijen N, Franklin RJ. Macrophage depletion impairs oligodendrocyte remyelination following lysolecithin-induced demyelination. Glia. 2001 Sep;35(3):204-12. 
Kotter MR, Zhao C, van Rooijen N, Franklin RJM. Macrophage-depletion induced impairment of experimental CNS remyelination is associated with a reduced oligodendrocyte progenitor cell response and altered growth factor expression. Neurobiology of Disease. 2005 Feb;18(1):166-75.

Kremer D, Schichel T, Förster M, Tzekova N, Bernard C, Van Der Valk P, et al. Human endogenous retrovirus type $\mathrm{W}$ envelope protein inhibits oligodendroglial precursor cell differentiation. Ann Neurol. 2013 Nov 1;74(5):721-32.

Kuhlmann T, Miron V, Cui Q, Cuo Q, Wegner C, Antel J, et al. Differentiation block of oligodendroglial progenitor cells as a cause for remyelination failure in chronic multiple sclerosis. Brain. Oxford University Press; 2008 Jul;131(Pt 7):1749-58.

la Fuente de AG, Errea O, van Wijngaarden P, Gonzalez GA, Kerninon C, Jarjour AA, et al. Vitamin $D$ receptor-retinoid $X$ receptor heterodimer signaling regulates oligodendrocyte progenitor cell differentiation. J Cell Biol. Rockefeller University Press; 2015 Dec 7;211(5):975-85.

Lang W, Rodriguez M, Lennon VA, Lampert PW. Demyelination and remyelination in murine viral encephalomyelitis. Ann N Y Acad Sci. 1984;436:98-102.

Lappe-Siefke C, Goebbels S, Gravel M, Nicksch E, Lee J, Braun PE, et al. Disruption of Cnp1 uncouples oligodendroglial functions in axonal support and myelination. Nature Genetics. Nature Publishing Group; 2003 Feb 18;33(3):366-74.

Lasiene J, Shupe L, Perlmutter S, Horner P. No evidence for chronic demyelination in spared axons after spinal cord injury in a mouse. J Neurosci. Society for Neuroscience; 2008 Apr 9;28(15):3887-96.

Lau LW, Keough MB, Haylock-Jacobs S, Cua R, Döring A, Sloka S, et al. Chondroitin sulfate proteoglycans in demyelinated lesions impair remyelination. Ann Neurol. Wiley Subscription Services, Inc., A Wiley Company; 2012 Sep;72(3):419-32.

Lee X, Shao Z, Sheng G, Pepinsky B, Mi S. LINGO-1 regulates oligodendrocyte differentiation by inhibiting ErbB2 translocation and activation in lipid rafts. Molecular and Cellular Neuroscience. 2014 May;60:36-42. 
Lee X, Yang Z, Shao Z, Rosenberg SS, Levesque M, Pepinsky RB, et al. NGF regulates the expression of axonal LINGO-1 to inhibit oligodendrocyte differentiation and myelination. J Neurosci. Society for Neuroscience; 2007 Jan 3;27(1):220-5.

Lee $\mathrm{Y}$, Morrison BM, Li Y, Lengacher S, Farah MH, Hoffman PN, et al. Oligodendroglia metabolically support axons and contribute to neurodegeneration. Nature. 2012 Jul $26 ; 487(7408): 443-8$.

Levine JM, Reynolds R. Activation and Proliferation of Endogenous Oligodendrocyte Precursor Cells during Ethidium Bromide-Induced Demyelination. Exp Neurol. 1999 Dec;160(2):333-47.

Levine JM, Reynolds R, Fawcett JW. The oligodendrocyte precursor cell in health and disease. Trends in Neurosciences. 2001;24(1):39-47.

Li W, Penderis J, Zhao C, Schumacher M, Franklin R. Females remyelinate more efficiently than males following demyelination in the aged but not young adult CNS. Exp Neurol. 2006 Nov;202(1):250-4.

Liebetanz D, Merkler D. Effects of commissural de- and remyelination on motor skill behaviour in the cuprizone mouse model of multiple sclerosis. Exp Neurol. 2006 Nov;202(1):217-24.

Lim DA, Alvarez-Buylla A. The adult ventricular-subventricular zone (V-SVZ) and olfactory bulb (OB) neurogenesis. Cold Spring Harb Perspect Biol. Cold Spring Harbor Lab; 2016 May 1;8(5):a018820.

Liu L, Cheung TH, Charville GW, Hurgo BMC, Leavitt T, Shih J, et al. Chromatin modifications as determinants of muscle stem cell quiescence and chronological aging. Cell Rep. Elsevier; 2013 Jul 11;4(1):189-204.

Lock C, Hermans G, Pedotti R, Brendolan A, Schadt E, Garren H, et al. Gene-microarray analysis of multiple sclerosis lesions yields new targets validated in autoimmune encephalomyelitis. Nat Med. 2002 May;8(5):500-8.

López-Otín C, Blasco MA, Partridge L, Serrano M, Kroemer G. The hallmarks of aging. Cell. Elsevier; 2013 Jun 6;153(6):1194-217. 
Lublin F, Miller DH, Freedman MS, Cree BAC, Wolinsky JS, Weiner $\mathrm{H}$, et al. Oral fingolimod in primary progressive multiple sclerosis (INFORMS): a phase 3, randomised, double-blind, placebo-controlled trial. Lancet. Elsevier; 2016 Mar 12;387(10023):1075-84.

Magalon K, Zimmer C, Cayre M, Khaldi J, Bourbon C, Robles I, et al. Olesoxime accelerates myelination and promotes repair in models of demyelination. Ann Neurol. Wiley Subscription Services, Inc., A Wiley Company; 2012 Feb;71(2):213-26.

Mason JL, Toews A, Hostettler JD, Morell P, Suzuki K, Goldman JE, et al. Oligodendrocytes and Progenitors Become Progressively Depleted within Chronically Demyelinated Lesions. The American Journal of Pathology. Elsevier; 2004 May;164(5):1673-82.

McMurran CE, Jones CA, Fitzgerald DC, Franklin RJM. CNS Remyelination and the Innate Immune System. Front Cell Dev Biol. Frontiers; 2016;4(e66308):38.

Mei F, Fancy SPJ, Shen Y-AA, Niu J, Zhao C, Presley B, et al. Micropillar arrays as a high-throughput screening platform for therapeutics in multiple sclerosis. Nat Med. Nature Publishing Group, a division of Macmillan Publishers Limited. All Rights Reserved; 2014 Jul 6;20(8):954-60.

Mei F, Guo S, He Y, Wang L, Wang H, Niu J, et al. Quetiapine, an atypical antipsychotic, is protective against autoimmune-mediated demyelination by inhibiting effector $\mathrm{T}$ cell proliferation. Feng Y, editor. PLoS ONE. Public Library of Science; 2012;7(8):e42746.

Meffre D, Massaad C, Grenier J. Lithium chloride stimulates PLP and MBP expression in oligodendrocytes via Wnt/ $\beta$-catenin and Akt/CREB pathways. Neuroscience. 2015 Jan $22 ; 284: 962-71$.

Mi S, Hu B, Hahm K, Luo Y, Kam Hui ES, Yuan Q, et al. LINGO-1 antagonist promotes spinal cord remyelination and axonal integrity in MOG-induced experimental autoimmune encephalomyelitis. Nat Med. 2007 Oct;13(10):1228-33.

Mi S, Lee X, Shao Z, Thill G, Ji B, Relton J, et al. LINGO-1 is a component of the Nogo-66 receptor/p75 signaling complex. Nat Neurosci. 2004 Mar;7(3):221-8.

Mi S, Miller RH, Lee X, Scott ML, Shulag-Morskaya S, Shao Z, et al. LINGO-1 negatively regulates myelination by oligodendrocytes. Nat Neurosci. 2005 Jun;8(6):745-51. 
Mi S, Miller RH, Tang W, Lee $\mathrm{X}, \mathrm{Hu} \mathrm{B,} \mathrm{Wu} \mathrm{W,} \mathrm{et} \mathrm{al.} \mathrm{Promotion} \mathrm{of} \mathrm{central} \mathrm{nervous} \mathrm{system}$ remyelination by induced differentiation of oligodendrocyte precursor cells. Ann Neurol. Wiley Subscription Services, Inc., A Wiley Company; 2009 Mar;65(3):304-15.

Milo R, Kahana E. Multiple sclerosis: geoepidemiology, genetics and the environment. Autoimmun Rev. 2010 Mar;9(5):A387-94.

Miron VE, Boyd A, Zhao J-W, Yuen TJ, Ruckh JM, Shadrach JL, et al. M2 microglia and macrophages drive oligodendrocyte differentiation during CNS remyelination. Nat Neurosci. Nature Research; 2013 Sep;16(9):1211-8.

Miron VE, Franklin RJM. Macrophages and CNS remyelination. Journal of Neurochemistry. 2014;130(2):165-71.

Miron VE, Ludwin SK, Darlington PJ, Jarjour AA, Soliven B, Kennedy TE, et al. Fingolimod (FTY720) enhances remyelination following demyelination of organotypic cerebellar slices. The American Journal of Pathology. Elsevier; 2010 Jun;176(6):2682-94.

Miron VE, Jung CG, Kim HJ, Kennedy TE, Soliven B, Antel JP. FTY720 modulates human oligodendrocyte progenitor process extension and survival. Ann Neurol. Wiley Subscription Services, Inc., A Wiley Company; 2008 Jan;63(1):61-71.

Mitsunaga Y, Ciric B, Van Keulen V, Warrington AE, Paz Soldan M, Bieber AJ, et al. Direct evidence that a human antibody derived from patient serum can promote myelin repair in a mouse model of chronic-progressive demyelinating disease. FASEB J. 2002 Aug;16(10):1325-7.

Moyon S, Huynh JL, Dutta D, Zhang F, Ma D, Yoo S, et al. Functional Characterization of DNA Methylation in the Oligodendrocyte Lineage. Cell Rep. 2016 Apr 26;15(4):748-60.

Nait-Oumesmar B, Decker L, Lachapelle F, Avellana-Adalid V, Bachelin C, Baron-Van Evercooren A. Progenitor cells of the adult mouse subventricular zone proliferate, migrate and differentiate into oligodendrocytes after demyelination. Eur J Neurosci. 1999 Dec;11(12):4357-66. 
Najm FJ, Madhavan M, Zaremba A, Shick E, Karl RT, Factor DC, et al. Drug-based modulation of endogenous stem cells promotes functional remyelination in vivo. Nature. 2015 Apr 20;522(7555):216-20.

Natrajan MS, la Fuente de AG, Crawford AH, Linehan E, Nuñez V, Johnson KR, et al. Retinoid X receptor activation reverses age-related deficiencies in myelin debris phagocytosis and remyelination. Brain. Oxford University Press; 2015 Dec;138(Pt 12):3581-97.

Nave K-A, Trapp BD. Axon-Glial Signaling and the Glial Support of Axon Function. Annu Rev Neurosci. 2008 Jul;31(1):535-61.

Nave K-A, Werner HB. Myelination of the nervous system: mechanisms and functions. Annu Rev Cell Dev Biol. Annual Reviews; 2014;30(1):503-33.

Nguyen TTT, Elsner RA, Baumgarth N. Natural IgM prevents autoimmunity by enforcing B cell central tolerance induction. J Immunol. American Association of Immunologists; 2015 Feb 15;194(4):1489-502.

Niehaus A, Shi J, Grzenkowski M, Diers-Fenger M, Archelos J, Hartung HP, et al. Patients with active relapsing-remitting multiple sclerosis synthesize antibodies recognizing oligodendrocyte progenitor cell surface protein: implications for remyelination. Ann Neurol. 2000 Sep;48(3):362-71.

Papadopoulos D, Rundle J, Patel R, Marshall I, Stretton J, Eaton R, et al. FTY720 ameliorates MOGinduced experimental autoimmune encephalomyelitis by suppressing both cellular and humoral immune responses. J Neurosci Res. Wiley Subscription Services, Inc., A Wiley Company; 2010 Feb 1;88(2):346-59.

Patrikios P, Stadelmann C, Kutzelnigg A, Rauschka H, Schmidbauer M, Laursen H, et al. Remyelination is extensive in a subset of multiple sclerosis patients. Brain. Oxford University Press; 2006 Dec;129(Pt 12):3165-72.

Pendleton JC, Shamblott MJ, Gary DS, Belegu V, Hurtado A, Malone ML, et al. Chondroitin sulfate proteoglycans inhibit oligodendrocyte myelination through PTPб. Exp Neurol. 2013 Sep;247:113-21. 
Pluchino S, Furlan R, Martino G. Cell-based remyelinating therapies in multiple sclerosis: evidence from experimental studies. Current Opinion in Neurology. 2004 Jun;17(3):247-55.

Preston M, Gong X, Su W, Matsumoto SG, Banine F, Winkler C, et al. Digestion products of the PH20 hyaluronidase inhibit remyelination. Ann Neurol. 2013 Feb;73(2):266-80.

Pringle N. PDGF receptors in the rat CNS: During late neurogenesis, PDGF alpha-receptor expression appears to be restricted to glial cells of the oligodendrocyte lineage. Development. 1992 Jul 23;115(2):535-51.

Raff MC, Miller RH, Noble M. A glial progenitor cell that develops in vitro into an astrocyte or an oligodendrocyte depending on culture medium. Nature. 1983 Jun 2;303(5916):390-6

Rivers LE, Young KM, Rizzi M, Jamen F, Psachoulia K, Wade A, et al. PDGFRA/NG2 glia generate myelinating oligodendrocytes and piriform projection neurons in adult mice. Nat Neurosci. 2008 Oct 8;11(12):1392-401.

Rodriguez M, Lennon VA, Benveniste EN, Merrill JE. Remyelination by oligodendrocytes stimulated by antiserum to spinal cord. J Neuropathol Exp Neurol. 1987 Jan;46(1):84-95.

Rosenberg SS, Kelland EE, Tokar E, la Torre De AR, Chan JR. The geometric and spatial constraints of the microenvironment induce oligodendrocyte differentiation. Proc Natl Acad Sci USA. National Acad Sciences; 2008 Sep 23;105(38):14662-7.

Ruckh JM, Zhao J-W, Shadrach JL, van Wijngaarden P, Rao TN, Wagers AJ, et al. Rejuvenation of regeneration in the aging central nervous system. Cell Stem Cell. Elsevier; 2012 Jan 6;10(1):96-103.

Schwartzbach CJ, Grove RA, Brown R, Tompson D, Then Bergh F, Arnold DL. Lesion remyelinating activity of GSK239512 versus placebo in patients with relapsing-remitting multiple sclerosis: a randomised, single-blind, phase II study. J Neurol. Springer Berlin Heidelberg; 2016 Nov $25 ;: 1-12$.

Sedel F, Bernard D, Mock DM, Tourbah A. Targeting demyelination and virtual hypoxia with highdose biotin as a treatment for progressive multiple sclerosis. Neuropharmacology. 2016 Nov;110(Pt B):644-53. 
Sedel F, Papeix C, Bellanger A, Touitou V, Lebrun-Frenay C, Galanaud D, et al. High doses of biotin in chronic progressive multiple sclerosis: a pilot study. Mult Scler Relat Disord. 2015 Mar;4(2):159-69.

Shen S, Sandoval J, Swiss VA, Li J, Dupree J, Franklin RJM, et al. Age-dependent epigenetic control of differentiation inhibitors is critical for remyelination efficiency. Nat Neurosci. Nature Publishing Group; 2008 Sep;11(9):1024-34.

Shields SA, Gilson JM, Blakemore W, Franklin RJ. Remyelination occurs as extensively but more slowly in old rats compared to young rats following fliotoxin-induced CNS demyelination. Glia. John Wiley \& Sons, Inc; 2000 Jan 1;29(1):102-2.

Sim FJ, Zhao C, Penderis J, Franklin RJM. The age-related decrease in CNS remyelination efficiency is attributable to an impairment of both oligodendrocyte progenitor recruitment and differentiation. J Neurosci. 2002 Apr 1;22(7):2451-9.

Simons M, Nave K-A. Oligodendrocytes: Myelination and Axonal Support. Cold Spring Harb Perspect Biol. Cold Spring Harbor Lab; 2016 Jan;8(1):a020479.

Sloane JA, Batt C, Ma Y, Harris ZM, Trapp B, Vartanian T. Hyaluronan blocks oligodendrocyte progenitor maturation and remyelination through TLR2. Proc Natl Acad Sci USA. National Acad Sciences; 2010 Jun 22;107(25):11555-60

Smith KJ, Blakemore WF, McDonald WI. Central remyelination restores secure conduction. Nature. 1979 Aug 2;280(5721):395-6.

Smith PM, Jeffery ND. Histological and ultrastructural analysis of white matter damage after naturally-occurring spinal cord injury. Brain Pathol. Blackwell Publishing Ltd; 2006 Apr;16(2):99-109

Snaidero N, Simons M. Myelination at a glance. J Cell Sci. The Company of Biologists Ltd; 2014 Jul 15;127(Pt 14):2999-3004.

Sobel RA, Ahmed AS. White Matter Extracellular Matrix Chondroitin Sulfate/Dermatan Sulfate Proteoglycans in Multiple Sclerosis. J Neuropathol Exp Neurol. The Oxford University Press; 2001 Dec 1;60(12):1198-207. 
Sousounis K, Baddour JA, Tsonis PA. Aging and regeneration in vertebrates. Curr Top Dev Biol. Elsevier; 2014;108:217-46.

Spassky N, de Castro F, Le Bras B, Heydon K, Quéraud-LeSaux F, Bloch-Gallego E, et al. Directional guidance of oligodendroglial migration by class 3 semaphorins and netrin-1. J Neurosci. 2002 Jul 15;22(14):5992-6004.

Stidworthy MF, Genoud S, Suter U, Mantei N, Franklin RJM. Quantifying the early stages of remyelination following cuprizone-induced demyelination. Brain Pathol. 2003 Jul;13(3):32939.

Syed YA, Hand E, Möbius W, Zhao C, Hofer M, Nave KA, et al. Inhibition of CNS remyelination by the presence of semaphorin 3A. J Neurosci. Society for Neuroscience; 2011 Mar 9;31(10):3719-28.

Tawk M, Makoukji J, Belle M, Fonte C, Trousson A, Hawkins T, et al. Wnt/beta-catenin signaling is an essential and direct driver of myelin gene expression and myelinogenesis. J Neurosci. Society for Neuroscience; 2011 Mar 9;31(10):3729-42.

Tomassy GS, Dershowitz LB, Arlotta P. Diversity Matters: A Revised Guide to Myelination. Trends in Cell Biology. Elsevier Ltd; 2016 Feb 1;26(2):135-47.

Tourbah A, Lebrun-Frenay C, Edan G, Clanet M, Papeix C, Vukusic S, et al. MD1003 (high-dose biotin) for the treatment of progressive multiple sclerosis: A randomised, double-blind, placebo-controlled study. Mult Scler. SAGE Publications; 2016 Nov;22(13):1719-31.

van Amerongen R, Nusse R. Towards an integrated view of Wnt signaling in development. Development. The Company of Biologists Ltd; 2009 Oct;136(19):3205-14.

van Horssen J, Bö L, Dijkstra CD, de Vries HE. Extensive extracellular matrix depositions in active multiple sclerosis lesions. Neurobiology of Disease. 2006 Dec;24(3):484-91.

van Wijngaarden P, Franklin RJM. Ageing stem and progenitor cells: Implications for rejuvenation of the central nervous system. Development (Cambridge). 2013;140(12):2562-75. 
Warrington AE, Bieber AJ, Ciric B, Pease LR, Van Keulen V, Rodriguez M. A recombinant human IgM promotes myelin repair after a single, very low dose. J Neurosci Res. Wiley Subscription Services, Inc., A Wiley Company; 2007 Apr;85(5):967-76.

Watanabe M, Hadzic T, Nishiyama A. Transient upregulation of Nkx2.2 expression in oligodendrocyte lineage cells during remyelination. Glia. Wiley Subscription Services, Inc., A Wiley Company; 2004 May;46(3):311-22.

Watzlawik J, Holicky E, Edberg DD, Marks DL, Warrington AE, Wright BR, et al. Human remyelination promoting antibody inhibits apoptotic signaling and differentiation through Lyn kinase in primary rat oligodendrocytes. Glia. Wiley Subscription Services, Inc., A Wiley Company; 2010 Nov 15;58(15):1782-93.

Watzlawik JO, Warrington AE, Rodriguez M. PDGF is required for remyelination-promoting IgM stimulation of oligodendrocyte progenitor cell proliferation. Stangel M, editor. PLoS ONE. Public Library of Science; 2013;8(2):e55149.

Williams A, Piaton G, Aigrot M-S, Belhadi A, Théaudin M, Petermann F, et al. Semaphorin 3A and 3F: key players in myelin repair in multiple sclerosis? Brain. Oxford University Press; 2007 Oct;130(Pt 10):2554-65.

Woodruff RH, Fruttiger M, Richardson WD, Franklin RJM. Platelet-derived growth factor regulates oligodendrocyte progenitor numbers in adult CNS and their response following CNS demyelination. Molecular and Cellular Neuroscience. 2004 Feb;25(2):252-62.

Yamaguchi W, Tamai R, Kageura M, Furuyama T, Inagaki S. Sema4D as an inhibitory regulator in oligodendrocyte development. Mol Cell Neurosci. 2012 Mar;49(3):290-9.

Ye F, Chen Y, Hoang T, Montgomery RL, Zhao X-H, Bu H, et al. HDAC1 and HDAC2 regulate oligodendrocyte differentiation by disrupting the beta-catenin-TCF interaction. Nat Neurosci. 2009 Jul;12(7):829-38. 
Yeung MSY, Zdunek S, Bergmann O, Bernard S, Salehpour M, Alkass K, et al. Dynamics of oligodendrocyte generation and myelination in the human brain. Cell. Elsevier; 2014 Nov 6;159(4):766-74.

Yilmaz ÖH, Katajisto P, Lamming DW, Gültekin Y, Bauer-Rowe KE, Sengupta S, et al. mTORC1 in the Paneth cell niche couples intestinal stem-cell function to calorie intake. Nature. Nature Research; 2012 Jun 28;486(7404):490-5.

Young KM, Psachoulia K, Tripathi RB, Dunn S-J, Cossell L, Attwell D, et al. Oligodendrocyte Dynamics in the Healthy Adult CNS: Evidence for Myelin Remodeling. Neuron. Elsevier; 2013 Mar;77(5):873-85.

Zalc B, Goujet D, Colman D. The origin of the myelination program in vertebrates. Curr Biol. Elsevier; 2008 Jun 24;18(12):R511-2.

Zawadzka M, Rivers LE, Fancy SPJ, Zhao C, Tripathi R, Jamen F, et al. CNS-resident glial progenitor/stem cells produce Schwann cells as well as oligodendrocytes during repair of CNS demyelination. Cell Stem Cell. Elsevier; 2010 Jun 4;6(6):578-90.

Zhang Y, Zhang H, Wang L, Jiang W, Xu H, Xiao L, et al. Quetiapine enhances oligodendrocyte regeneration and myelin repair after cuprizone-induced demyelination. Schizophr Res. 2012 Jun;138(1):8-17.

Zhao C, Fancy SPJ, Franklin RJM, ffrench-Constant C. Up-regulation of oligodendrocyte precursor cell $\alpha \mathrm{V}$ integrin and its extracellular ligands during central nervous system remyelination. Bansal R, Macklin WB, de Vellis J, editors. J Neurosci Res. Wiley Subscription Services, Inc., A Wiley Company; 2009 Nov 15;87(15):3447-55.

Zhu X, Hill RA, Nishiyama A. NG2 cells generate oligodendrocytes and gray matter astrocytes in the spinal cord. Neuron Glia Biol. Cambridge University Press; 2008 Feb;4(1):19-26. 